\title{
Analysis of the Effects of Streamwise Lift Distribution on Sonic Boom Signature
}

\author{
Seung Y. Yoo ${ }^{1}$ \\ NASA Dryden Flight Research Center, Edwards, CA, 93523
}

\begin{abstract}
The streamwise lift distribution of a wing-canard-stabilator-body configuration was varied to study its effect on the near-field sonic boom signature. The investigation was carried out via solving the three-dimensional Euler equation with the OVERFLOW-2 flow solver. The computational meshes were created using the Chimera overset grid topology. The lift distribution was varied by first deflecting the canard then trimming the aircraft with the wing and the stabilator while maintaining constant lift coefficient of 0.05 . A validation study using experimental results was also performed to determine required grid resolution and appropriate numerical scheme. A wide range of streamwise lift distribution was simulated. The result shows that the longitudinal wave propagation speed can be controlled through lift distribution thus controlling the shock coalescence.
\end{abstract}

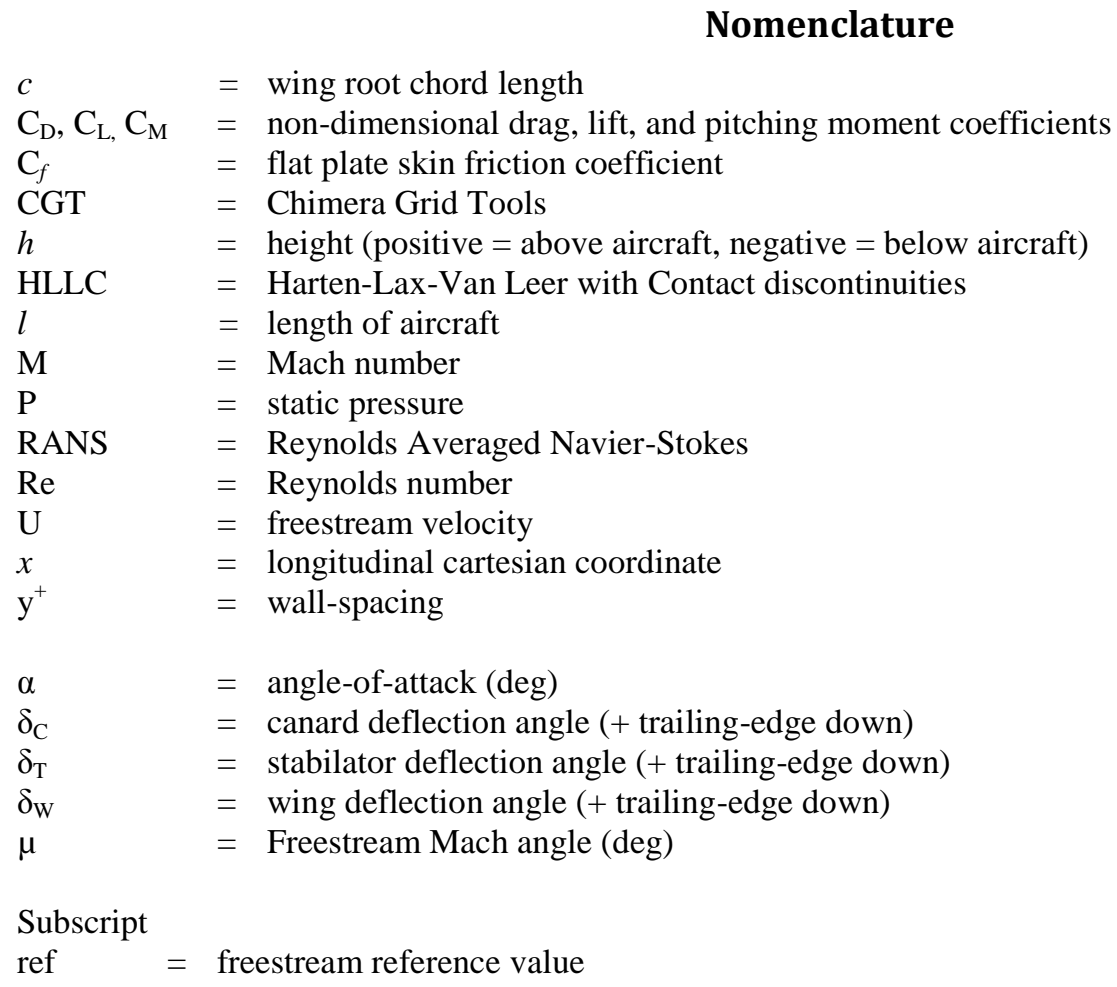

\section{Introduction}

TNESTIGATION of sonic boom has been one of the major areas of study in aeronautics due to the benefits a low-boom aircraft has in both civilian and military applications. Current Federal Aviation Administration

\footnotetext{
${ }^{1}$ Aerospace engineer, Aerodynamics and Propulsion Branch, P.O. Box 273/MS 4840D.
} 
regulations prohibit supersonic flight over land due to potential effects the sonic boom may have on structures and humans. Consequently, numerous studies have been performed to investigate the characteristics of shock systems. The topic of special interest is the effect of streamwise lift distribution has on sonic boom. It is known that the lift affects the strength of the shock generated on the lifting surface, thus affecting the relative longitudinal propagation speed of the shock system. As the shock coalescence effect is the result of shocks having differential longitudinal propagation speed with respect to with other, it is possible to control this phenomenon via streamwise lift distribution.

The effect of the streamwise lift distribution on the sonic boom was first investigated by Ferri ${ }^{1}$ in 1969. Using a series of simple tandem wing configurations with varying distance and size, Ferri showed that the strength of the bow shock can be reduced by increasing the amount of lift carried near the nose of the configuration. This research was extended by Fomin ${ }^{2}$ who investigated the influence of the streamwise lift distribution on the acoustic parameters using an aircraft model in a tandem wing configuration with different wing areas. The result showed that acoustic shock level can be reduced through proper distribution of lift along the length of the airframe.

The effect of varying lift distribution on shock position and strength was investigated in flight in the Lift and Nozzle Change Effect on Tail Shock ${ }^{3}$ (LaNCETS) project initiated at NASA Dryden Flight Research Center. Two aircraft were used for the project: 1) NASA aircraft NF-15B, tail No.837 (NASA837) and 2) NASA aircraft F-15B, tail No. 836 (NASA836). NASA837, equipped with canard and variable area ratio nozzle, was utilized as the research aircraft while NASA836 served as the probing aircraft in the near-field. The lift distribution of the research aircraft was varied by deflecting the canard while maintaining trimmed level flight.

The study presented in this paper directly supports the LaNCETS project with the computational analysis on the effect of streamwise lift distribution variation on shock. A simplified wing-canard-stabilator-body model was utilized instead of a full NASA837 in order to validate the computational tools, simplify the problem, and isolate the effects that may influence the sonic boom. The lift distribution was varied via canard deflection as it was done during flight. The angle of attack and the lift coefficient were kept constant for all configurations. In addition, all configurations were trimmed to steady, leveled flight.

The computational approach is first described in this paper. A code validation study using a delta wing-body wind tunnel test case is described in Section III. The results of the lift distribution on the sonic boom signature are discussed in Section IV.

\section{A. Flow Solver}

\section{Methods}

OVERFLOW- $2^{4}$ was chosen as the flow solver. OVERFLOW-2 is a viscous, compressible, three-dimensional Reynolds Averaged Navier-Stokes (RANS) solver specifically designed to utilize the structured Chimera overset grid $^{5}$ topology. It is a robust and comprehensive solver capable of employing various dissipation schemes, numerical schemes, flux limiters, and turbulence models. Although OVERFLOW-2 is a viscous flow solver, viscosity was not employed in majority of this study since viscous effects are negligible in sonic boom pressure signature ${ }^{6}$. However, viscosity was employed on conditions with numerical instability resulting from flow separations. The viscous calculations were done fully turbulent using wall-function of Spalart-Allmaras ${ }^{7}$ turbulence model. The numerical scheme used throughout the study, the Harten-Lax-Van Leer with contact discontinuities ${ }^{8,9}$ (HLLC) scheme, was chosen based on the scheme study performed in the validation section (Section III). Multigrid and grid sequencing algorithm were used to accelerate convergence rate.

\section{B. Computational Mesh}

The computational meshes were created using the Chimera overset grid $^{5}$ topology. This method simplifies the grid generation of geometrically complex multi-body configurations by allowing the user to construct the mesh from sets of relatively simple, overlapping, body-fitted grids. The process of grid generation was further streamlined by creating the mesh using the script library of Chimera Grid Tools ${ }^{10}$ (CGT) v2.0. CGT is a comprehensive package containing variety of tools for creating grids using Chimera overset method. It contains tools for grid generation, manipulation, visualization, and diagnostic purpose. It can run in batch mode under the OVERGRID graphical interface or in scripting fashion using its extensive script library. The body-fitted computational meshes for viscous computation were created with non-dimensionalized wall-spacing, $\mathrm{y}^{+}$, of approximately +50 . The $\mathrm{y}^{+}$was calculated using White's ${ }^{11}$ method shown in Equation 1 and Equation 2. 


$$
\begin{aligned}
y^{+} & =\operatorname{Re}_{r e f} \sqrt{\frac{C_{f}}{2}} y \\
C_{f} & =\frac{0.455}{\ln ^{2}\left(0.06 \operatorname{Re}_{x}\right)}
\end{aligned}
$$

$\mathrm{Re}_{\mathrm{x}}$ denotes the Reynolds number at certain downstream distance, $x$ ( $x$ is typically set as the $10 \%$ of the reference length). The $y$ denote the normal distance from the surface and $\mathrm{C}_{f}$ denote the skin friction coefficient of a flat plate.

The far-field grid was created aligned to the far-field Mach angle to improve the accuracy of the captured sonic boom. The far-field Mach angle was calculated using Eq. (3) ${ }^{12}$, shown below. The computational domain was extended out to 1 body-length in upstream and downstream direction and 2 body-lengths in spanwise direction. The domain connectivity was performed using Meakin's X-Ray Object method ${ }^{13}$ with double-fringe overlapping between all grids.

$$
\mu=\sin ^{-1}\left(\frac{1}{M_{r e f}}\right)
$$

\section{Variation of Streamwise Lift Distribution}

A simple wing-canard-stabilator-body model was created to isolate the effect of lift distribution on shock. Propulsion devices such as inlet and nozzle were not modeled to limit the source of lift and shock systems. Features such as nose-boom, boat-tail, and wing-strakes were not modeled geometric simplicity. A symmetrical diamond airfoil with 5\%c maximum thickness at $50 \% x / c$ was used for the wing, canard, and stabilator. All three lifting surfaces have approximately $45^{\circ}$ leading-edge sweep. The fuselage was modeled as an axisymmetric body. The center of

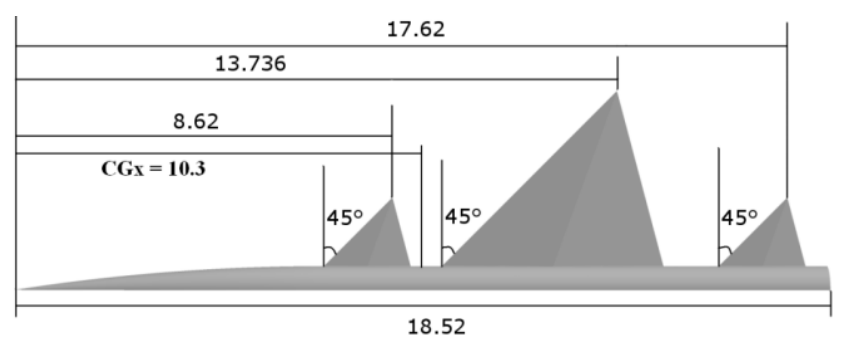

Figure 1. Wing-canard-stabilator-body model gravity was placed on the symmetry plane, 10.3 non-dimensionalized distances from the nose. The half-body model is shown in Figure 1. Some of the general features of NASA837 were conserved in the simplified wing-canardstabilator-body model such as the span-to-chord ratio and the location of the individual lifting surfaces.

As previously mentioned, the streamwise lift distribution was varied by deflecting the canard. Current method differs from that used by Ferri ${ }^{1}$ and Fomin ${ }^{2}$ which involved changing the size of the lifting surfaces to change the streamwise lift distribution. There are two advantages to changing the streamwise lift distribution via canard deflection. First, the aerodynamic center of individual lifting surfaces remains constant for different configurations. This eliminates effects that may result from having wings of different size. Second, the experiment is flight testable. Although it is possible to change the wing between the flight tests, the downtime and the cost associated the configuration change makes the test inefficient and impractical. The following procedure lists the steps for changing the streamwise lift distribution.
1. Deflect the canard
2. Deflect the wing to reach the desired lift coefficient $\left(C_{L}=0.05 \pm 0.003\right)$
3. Deflect the stabilator to trim the configuration $\left(C_{M}=0.0 \pm 0.005\right)$
4. Iterate between Step 2 to Step 3 until the configuration is trimmed at desired lift coefficient

The deflections were considered positive for trailing-edge down. Lifting devices such as flaps and slats were not modeled for computational simplicity; instead, entire lifting surface was deflected as the control surface. A tool that proved to be very useful during this process was Missile DATCOM v. $707^{14,15}$. Missile DATCOM is a preliminary design tool for estimating the aerodynamic forces and moment coefficient as well as control derivatives. It is capable of modeling missile-like geometries with various fins, nozzle, inlets, and protrusions. The lifting surface deflections were initially determined using Missile DATCOM v.707 then refined using OVERFLOW-2 inviscid results. 
The lift coefficient was kept constant at approximately $0.050 \pm 0.003$ for all configurations. The lift coefficient was chosen based on the requirement for numerical stability of the inviscid simulations. The configuration was considered trimmed if the moment coefficient was $0.000 \pm 0.005$. The angle-of-attack was fixed at $1.5^{\circ}$. The altitude and Mach number was matched to one of the major test point flown in the LaNCETS project: Mach 1.4 at altitude $40,000 \mathrm{ft}$.

\section{Validation Study: $69^{\circ}$ delta wing-body}

A numerical validation study was performed to determine the baseline grid resolution and investigate the performance of different numerical schemes. In addition, the force and moment coefficients from Missile DATCOM v.707 were compared to the inviscid result of OVERFLOW-2 for various angle-ofattacks.

The "model 4" geometry described in a 1973 wind-tunnel study by Huntun, Hicks, and Mendoza ${ }^{16}$ was selected as the validation model due to ample wind-tunnel data provided in the study. The model is comprised of an axisymmetric fuselage with a $69^{\circ}$ leading-edge swept delta wing, shown in Figure 2. The

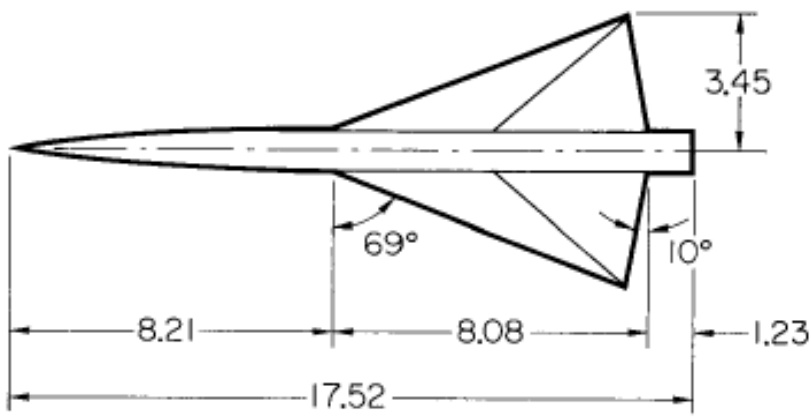

Figure 2. "Model 4" wing-body validation model ${ }^{16}$. airfoil of the wing is the symmetrical diamond airfoil with $5 \% c$ maximum thickness at $50 \% x / c$.

Due to lack of a sting geometry description, it was approximated by digitizing and extrapolating the data from a sketch of a wind-tunnel apparatus provided in the wind-tunnel study.

The validation was performed against a non-lifting case $\left(\mathrm{C}_{\mathrm{L}}=0.0, \alpha=0.0^{\circ}\right)$ and a lifting case $\left(\mathrm{C}_{\mathrm{L}}=0.08, \alpha=\right.$ $\left.2.56^{\circ}\right)$ at freestream Mach number of 1.68. The freestream Mach angle, calculated using Eq.1, was $36.5^{\circ}$ for the non-lifting case. The freestream Mach angle was adjusted for the lifting-case. The near-field pressure signature was measured parallel to the freestream velocity at $h / l=+3.6$ on the symmetry plane. The computational surface mesh and the volume mesh are shown in Figure 3.

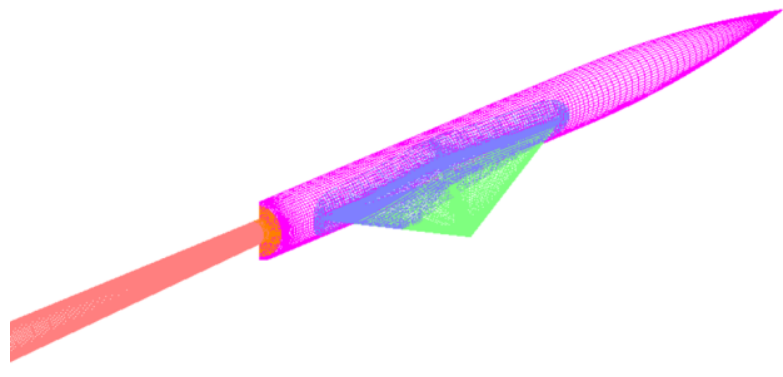

a)

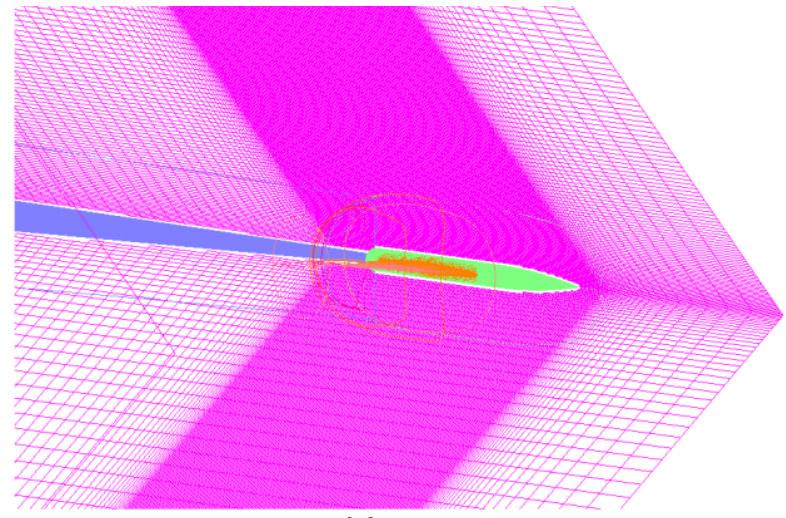

b)

Figure 3. Validation model grid. (a) surface grid, (b) volume grid.

\section{A. Grid Resolution Study}

Grids of different densities were simulated to determine the base resolution required to accurately capture the propagating shock. The grid dimensions are tabulated in Table 1, shown below.

\begin{tabular}{|c|c|c|c|c|}
\hline Grid & $\begin{array}{c}\text { Mach-Aligned } \\
\text { Far-Field }(\mathrm{J} \times \mathrm{K} \times \mathrm{L})\end{array}$ & Body $(\mathrm{J} \times \mathrm{K} \times \mathrm{L})$ & Wing $(\mathrm{J} \times \mathrm{K} \times \mathrm{L})$ & Sting $(\mathrm{J} \times \mathrm{K} \times \mathrm{L})$ \\
\hline $0.5 \mathrm{x}$ & $241 \times 204 \times 89$ & $110 \times 25 \times 25$ & $97 \times 20 \times 25$ & $60 \times 61 \times 25$ \\
\hline $1 \mathrm{x}$ & $369 \times 304 \times 89$ & $193 \times 50 \times 50$ & $197 \times 40 \times 50$ & $136 \times 61 \times 50$ \\
\hline $2 \mathrm{x}$ & $625 \times 504 \times 145$ & $373 \times 100 \times 100$ & $397 \times 80 \times 100$ & $263 \times 61 \times 100$ \\
\hline
\end{tabular}

Table 1. Grid Resolution for Validation Study 
The resolution of the Mach-aligned far-field grid was varied only in the regions of interest: the upstream and the region of shock propagation. Although this method would have been invalid for subsonic and transonic flows, it is valid in supersonic flow regime since the flow generally propagates toward downstream. It has been shown in a wind tunnel test that supersonic flow can propagate in the upstream direction within the boundary layer region ${ }^{17}$. However, for this test, it can be assumed that flow does not propagate upstream.

The normalized propagated pressure of the $0.5 \mathrm{x}$, $1 \mathrm{x}$, and $2 \mathrm{x}$ grids were compared against the windtunnel data in Figure 4. As shown in the figure, the effect from increasing grid resolution is negligible except in the body-sting connection region. However, the difference in the result between different grid resolutions is negligible. Overall the computational results are in agreement with the experimental data ${ }^{16}$ for a zero-lift condition.

Comparison between the inviscid OVERFLOW-2 simulation and the wind tunnel measurement for $\mathrm{C}_{\mathrm{L}}$ of 0.08 is shown in Figure 5. The bow shock and the wing shocks show excellent agreement. An extra shock, shown in CFD but not present in wind-tunnel data, at $1.1 \leq \mathrm{x} / \mathrm{l} \leq 1.3$ is the compression and the expansion of pressure between the wing and the tail. The cause of its existence in CFD may be due to inaccurate sting geometry or lack of viscous effects. Similar result for the tail is shown in other validation attempts done by Casper $^{18}$ and Wintzer ${ }^{19}$. Both Casper and Wintzer used CART3D compressible inviscid flow solver with grid adaptation.

\section{B. Numerical Scheme Study}

Different numerical schemes were compared to investigate the affects the schemes may have in capturing the shock. The non-lifting case was used for this portion of the study. The $1 \mathrm{x}$ grid, described in Table 1, was chosen as the grid resolution of choice. The numerical schemes compared were Roes upwind, HLLC upwind ${ }^{8,9}$, AUSM ${ }^{20}$, and Yee's Total Variation Diminishing (TVD) scheme ${ }^{21}$, shown in Figure 6. The numerical simulations were done using $3^{\text {rd }}$ order spatial accuracy for Roes upwind, HLLC upwind, and ASUM+. The TVD scheme was simulated using $2^{\text {nd }}$ order spatial accuracy. The HLLC scheme was also compared against the $5^{\text {th }}$ order Weighted Essentially Non-Oscillatory $^{22}$ (WENO5) and Weighted Essentially Non-Oscillatory Modified $^{22}$ (WENO5M) schemes, shown in Figure 7.

As shown in Figure 6, Yee's TVD has higher dissipation compared to Roes and HLLC scheme. It is also noticeable that ROES and HLLC scheme produce almost identical results. The $3^{\text {rd }}$ order AUSM+ scheme and the $5^{\text {th }}$ order WENO5 and WENO5M schemes produces unphysical undershoots and overshoots

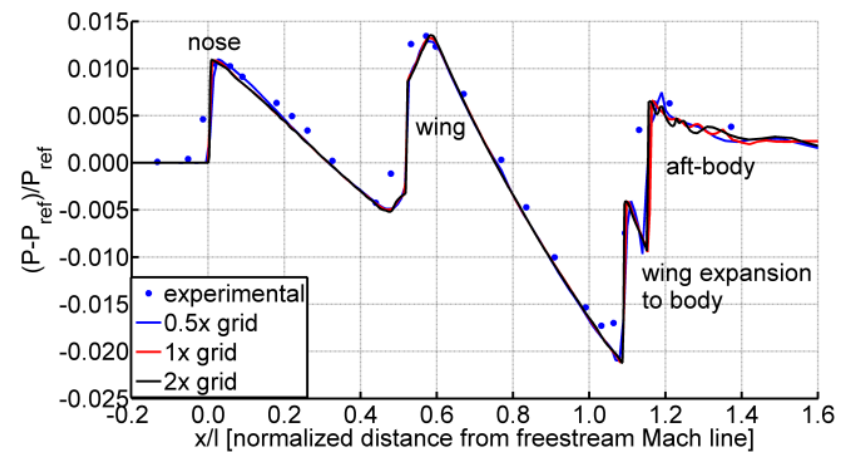

Figure 4. Validation grid resolution study result $\left(C_{L}=0\right)$. Experimental data from Ref. 16.

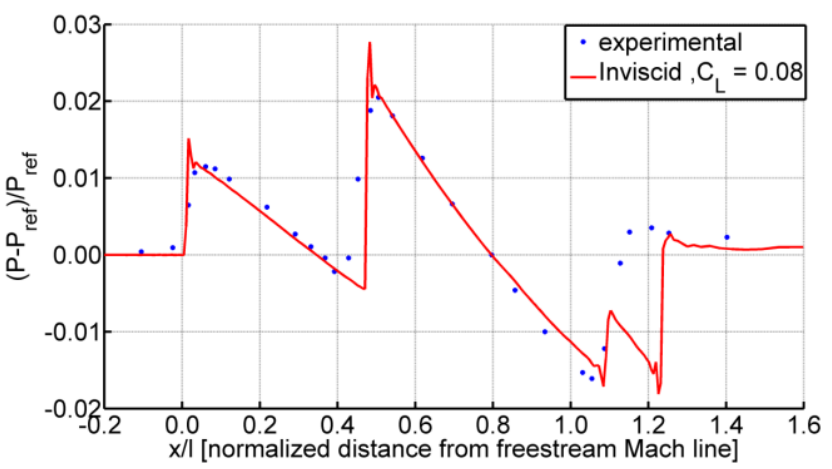

Figure 5. Validation grid resolution study result $\left(C_{L}=0.08\right)$. Experimental data from Ref. 16.

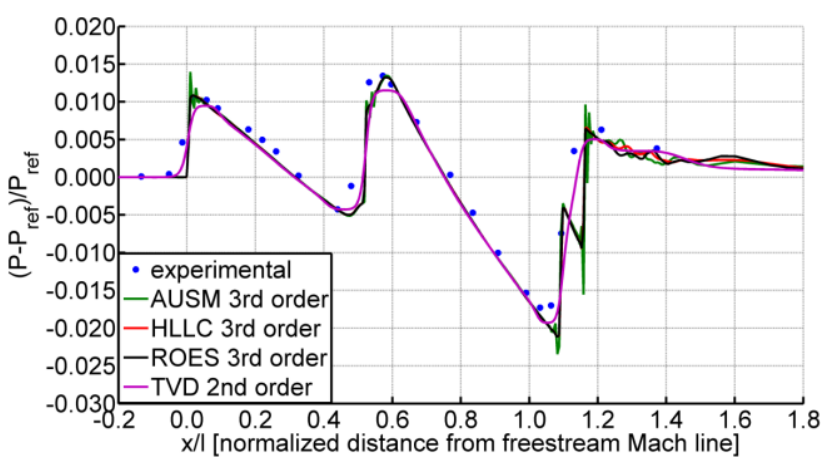

Figure 6. $2^{\text {nd }}$ and $3^{\text {rd }}$ order numerical scheme comparison. Experimental data from Ref. 16:

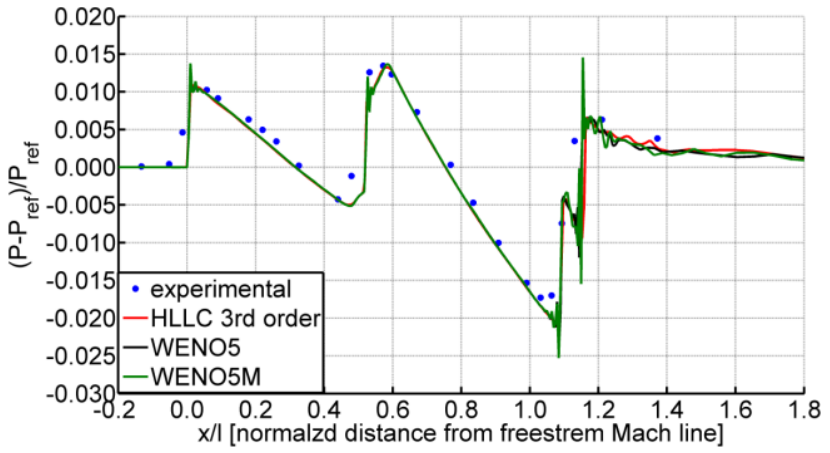

Figure 7. $3^{\text {rd }}$ order and $5^{\text {th }}$ order numerical scheme comparison. Experimental data from Ref. 16: 
around the shock. These effects may be partially mitigated by doing the full viscous simulation.

The scheme chosen for the rest of the study, based on the scheme comparison results, is the HLLC scheme. Although HLLC and Roes upwind scheme produced similar results, HLLC was chosen due to higher theoretical robustness compared to the ROES upwind scheme ${ }^{8}$.

\section{Missile DATCOM v.707 and OVERFLOW-2 Comparison}

The lift, drag, and pitching moment coefficients of the validation model estimated using Missile DATCOM v.707 were compared against that from OVERFLOW-2 inviscid simulation. The $1 \mathrm{x}$ grid, described in Table 1, was utilized for the OVERFLOW-2 simulation. The comparison was necessary since Missile DATCOM was used to initially determine the lifting surface deflection of the model used in the streamwise lift distribution study. The lift and pitching moment coefficients were compared for various angles-of-attack. The result is plotted in Figure 8. The result shows excellent agreement between Missile DATCOM v.707 and OVERFLOW-2 for low angle-of-attack. Although the range of angle-of-attacks compared is limited, it is sufficient for this study.

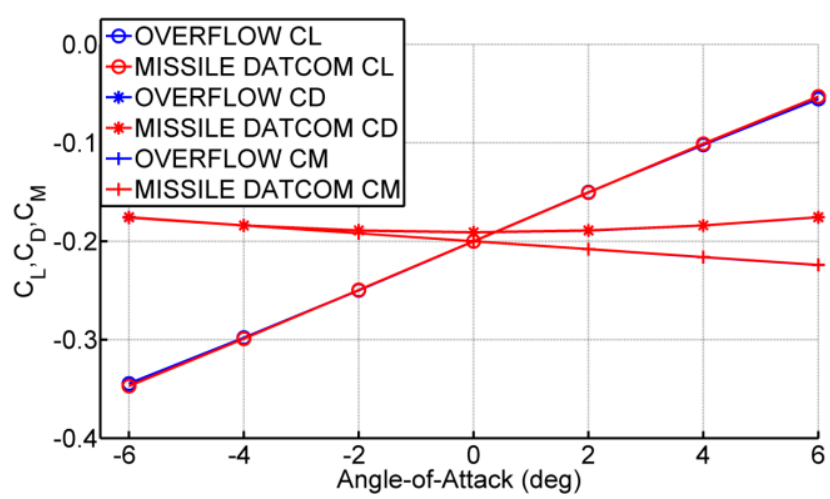

Figure 8. Missile DATCOM and Overflow-2 inviscid result comparison: $C_{L}, C_{D}, C_{M}$.

\section{Streamwise Lift Distribution Variation Study: wing-canard-stabilator-body}

Total of four configurations were analyzed in this study. The configurations are summarized in Table 2 , shown below. Configurations 1, 2, and 3 were tested in flight; Configuration 4 was added to the test matrix for completeness and Configuration 0 was utilized only for the grid independence study.

\begin{tabular}{|c|c|c|c|}
\hline Configuration \# & Canard Deflection (deg) & Wing Deflection (deg) & $\begin{array}{c}\text { Stabilator deflection } \\
(\mathrm{deg})\end{array}$ \\
\hline 0 & 0.0 & 0.0 & 0.0 \\
\hline 1 & -5.5 & 0.3 & -6.0 \\
\hline 2 & 0 & -1.1 & 0.0 \\
\hline 3 & +3.3 & -1.4 & 1.0 \\
\hline 4 & +5.5 & -1.8 & 3.0 \\
\hline
\end{tabular}

Table 2. Descriptions of test configurations.

The lift generated by individual lifting surfaces for different configurations are shown in Figure 9. As previously mentioned, the lift coefficient was constant $\left(\mathrm{C}_{\mathrm{L}}=0.05\right)$ and angle-of-attack was fixed at $1.5^{\circ}$ for Configurations 1 through 4 . Comparing the configurations, Configuration 1 generates largest positive lift with wing and largest negative lift with canard and stabilator. Configuration 2 generates positive lift on wing, canard, and stabilator. However, the lift on wing is significantly less than that generated by Configuration 1. Configurations 3 and 4 generate negative lift with wing and positive lift with canard and stabilator. It is clear to see that configurations tested span a wide, if not full, range of lift that could be distributed over an aircraft.

The flow around Configuration 4 was resolved with viscosity due to flow separation at the stabilator.

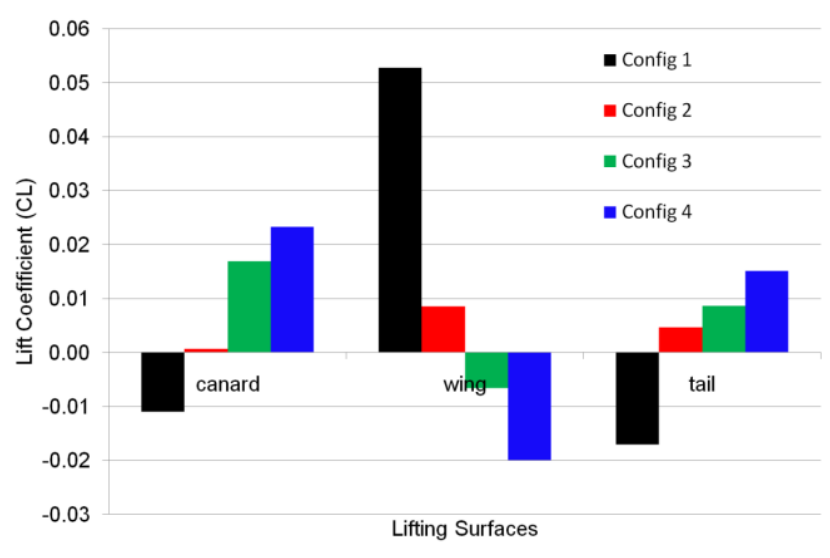

Figure 9. Lift generated by individual lifting surfaces for different configurations. 
Configurations 1, 2, and 3 were computed without viscosity. All propagated pressures were measured parallel to the freestream velocity, at $h / l=-1.6$ on the symmetry plane which is approximate location of the probing aircraft during the flight. The freestream Mach angle, at Mach 1.4, was 45.6 .

\section{A. Grid Independence Study}

The grid independence study was performed to determine the grid resolution required to accurately capture the propagated shock. Configuration 0 was used for this study. Due to a large number of grid points in the Mach-aligned far-field grid, the grid independence study was done separately for the body-fitted grids and the mach-aligned far-field grid. The body-fitted grid and the Mach-aligned far-field grid were tested at angle-ofattack of $1.5^{\circ}$ and $2.0^{\circ}$, respectively. The grid independence was established based on the pressure instead of the force and moment coefficients since this

study strictly focuses on the pressure signature. The grid dimensions for the body-fitted grids and the Machaligned far-field grids are tabulated in Table 3 and Table 4 , respectively. The grid independence of the bodyfitted grids was established by comparing the surface pressure of $0.5 \mathrm{x}, 1 \mathrm{x}$, and $2 \mathrm{x}$ grids, as shown in Figure 10. It is clear from the figure that surface pressure does not change with the increase in the grid resolution, thus establishing grid independence at $0.5 \mathrm{x}$ grid resolution. Similarly, the grid independence of the mach-aligned far-field grid was established by comparing the propagated pressure for $1 \mathrm{x}, 2 \mathrm{x}$, and $3 \mathrm{x}$ grid, shown in Figure 11. The grid independence was established at $1 \mathrm{x}$ grid resolution both body-fitted and far-field.

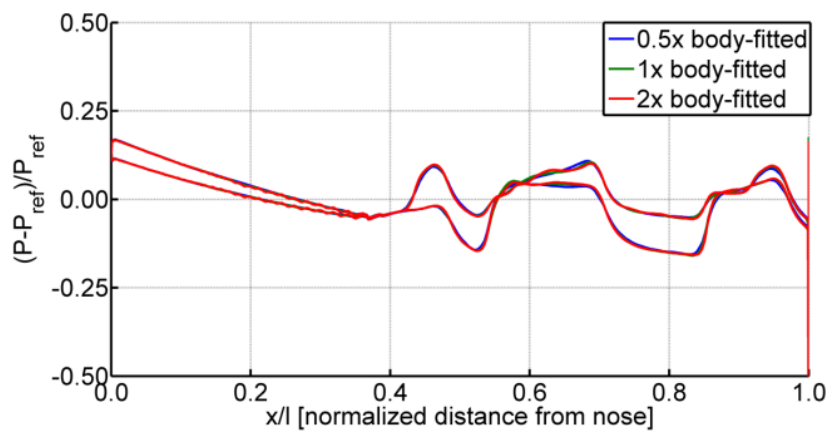

Figure 10. Wing-canard-stabilator-body body-fitted grid independence study.

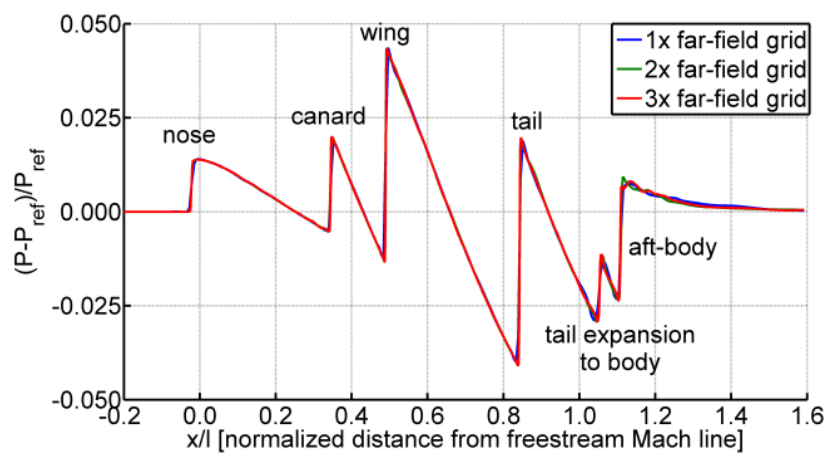

Figure 11. Wing-canard-stabilator-body body-fitted grid independence study.

\begin{tabular}{|c|c|c|c|}
\hline Grid & $\begin{array}{c}\text { Bodys } \\
(\mathrm{J} \times \mathrm{K} \times \mathrm{L})\end{array}$ & $\begin{array}{c}\text { Lifting Surfaces } \\
(\mathrm{J} \times \mathrm{K} \times \mathrm{L})\end{array}$ & $\begin{array}{c}\text { Collar } \\
(\mathrm{J} \times \mathrm{K} \times \mathrm{L})\end{array}$ \\
\hline $0.5 \mathrm{x}$ & $241 \times 30 \times 25$ & $97 \times 20 \times 25$ & $97 \times 19 \times 35$ \\
\hline $1 \mathrm{x}$ & $280 \times 50 \times 50$ & $197 \times 40 \times 50$ & $197 \times 39 \times 50$ \\
\hline $2 \mathrm{x}$ & $348 \times 120 \times 50$ & $397 \times 159 \times 100$ & $397 \times 79 \times 100$ \\
\hline
\end{tabular}

Table 3: Body-fitted grid study dimensions

\begin{tabular}{|c|c|}
\hline Grid & Far-field $(\mathrm{J} \times \mathrm{K} \times \mathrm{L})$ \\
\hline $1 \mathrm{x}$ & $297 \times 225 \times 105$ \\
\hline $2 \mathrm{x}$ & $553 \times 455 \times 105$ \\
\hline $3 \mathrm{x}$ & $809 \times 655 \times 105$ \\
\hline
\end{tabular}

Table 4: Mach-aligned far-field grid study dimensions

\section{B. Effect of Streamwise Lift Distribution Variation on Shock}

The normalized propagated shock is plotted in Figure 12 for different streamwise lift distributions represented by various canard deflections. The lift generated by individual lifting surfaces for different configurations are shown in Figure 9. More details of shock system are visible for Configuration 4 due to the effect of viscosity.

As mentioned briefly in the Introduction section, the compression and expansion waves of a large shock system propagate faster in forward and aft direction, respectively, than that of a smaller shock system. Consequently, the phenomenon of shock coalescence occurs because the waves of a larger shock system catches up to that of a smaller shock system. In addition, it is known that the strength of the shock generated increases with the increase in lift generated by the lifting surface. Thus it is possible to control relative speed of the shock propagation through engineered distribution of streamwise lift. Consequently, it is possible to control the shock coalescence. 
A conventional wing-tail configuration aircraft generates most of the lift with the wing while using the tail as the trimmer. Thus the shock generated on the wing is significantly stronger than that generated on the tail. As shock systems propagate toward the ground, the compression wave from the wing catches up to the nose shock system and coalesce with it. Similarly, the expansion wave from the wing coalesces with the shock system from the tail. Consequently, although many shock systems were generated on the aircraft, only two shocks are heard on the ground; the bow shock and tail shock. A similar shock system is shown in Figure 12 on Configuration 1.

Examining the lift distribution and the pressure signature of Configuration 1, the wing generates large

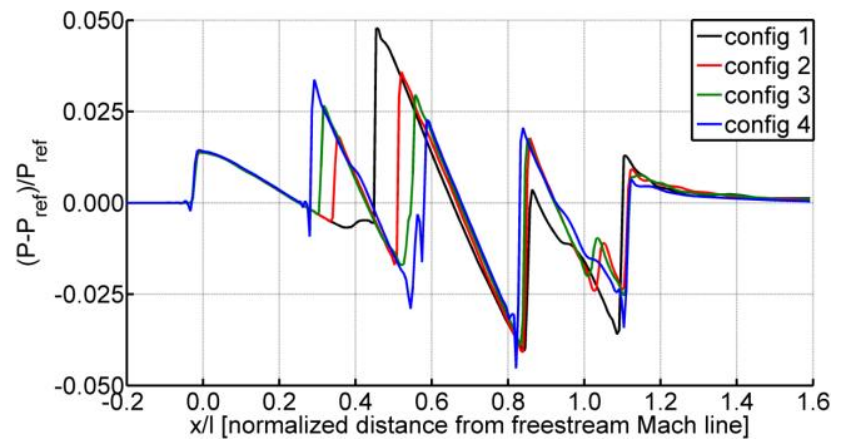

Figure 12. Propagated sonic boom of wing-canardstabilator-body at $h / l=-1.6$ for different configurations.

amount of positive lift while the canard and stabilator generates negative lift. Such lift distribution generates a large shock system which propagates much faster than the shocks system generated on the canard and the tail. The figure shows that difference in speed of propagation is large enough for the compression wave of the wing to coalesce with the shock system of the canard within 1.6 body-lengths. It is also noticeable that expansion wave from the tail has coalesced with the expansion wave of the tail.

However, it is also possible to prevent shocks from coalescing. Knowing that shock propagation in forward and aft direction is proportional to the strength of the shock, one can prevent shock coalescence by generating shocks of approximately same strength for all lifting surfaces. Such shock system would not coalesce while propagating toward the ground since all shock systems would be propagating forward and aft at same speed. Such case is shown in Figure 12 on Configuration 3.

Configuration 3 has its wing generating negative lift while the canard and the stabilator are generating positive lift. This lift distribution generates shock systems of approximately equal strength for the wing, canard, and the stabilator. It is shown in figure that shocks of the three lifting surfaces have not coalesced within 1.6 body-lengths. In addition, the expansion wave from the tail is still a separate shock from the expansion wave of the tail. It is also noticeable that strengths of shock system of wing, stabilator, and canard are still approximately equal. As the shock systems propagate toward the ground, the shock system of the canard is likely to coalesce with the shock system of the nose. Similarly, the shock system of the stabilator is likely to coalesce with the shock system of the tail. However, unlike the conventional aircraft, three relatively weaker shock systems will hit the ground instead of a single strong shock system. Configurations 2 and 4 show intermediate shock system compared to Configurations 1 to 3. Same trends were shown in the LaNCETS flight data.

It can be concluded from above observation that it is possible to prevent shocks from coalescing with one another. By default the wing generates the most amount of lift thus produce strong shock compared to canard and stabilator. Thus as the shock systems propagate from the aircraft toward the ground, the shock system of individual lifting surfaces coalesce due to different forward and aft propagation speed. However, with careful distribution of lift, it is possible to various lifting surfaces to generate shocks of approximately equal strength which would have equal forward and aft propagation speed, thus preventing shock interaction.

\section{Conclusion}

The effect of change in streamwise lift distribution on sonic boom and the shock structure was investigated using a simple wing-canard-stabilator-body configuration. The study demonstrated the ability to control the shock coalescence by controlling the shock system's relative longitudinal propagation speed using streamwise lift distribution. The result also showed that it could be more advantageous for aircraft to offload the lift from the wing to stabilator and canard to prevent shocks from coalescing in the near-field region. An extensive validation study was performed to determine the base grid resolution and the effects of different numerical schemes which increase the confidence in the result. 


\section{References}

${ }^{1}$ Ferri, A., Ismail, A., "Effects of Lengthwise Lift Distribution on Sonic Boom of SST Configurations," AIAA Journal Vol. 7, No. 8, 1969.

${ }^{2}$ Fomin, V.M., Volkov, V.F., Chirkashenko, V.F., "Influence of Lift Redistribution Along the Length of a Supersonic Airplane on the Acoustic-Shock Parameters", Journal of Engineering Physics and Thermophysics, Vol. 80, No. 5, 2007, pp.874884

${ }^{3}$ Moes, T., "Sonic Boom Research at NASA Dryden: Objectives and Flight Results from the Lift and Nozzle Change Effects on tail Shock (LaNCETS) Project", International Test \& Evaluation Association, Feb. 2009.

${ }^{4}$ Nichols, R.H., Buning, P.G., "User's Manual for OVERFLOW 2.1: Version 2.1t", Aug. 2008.

${ }^{5}$ Benek, J.A., Buning, P.G., Steger, J.L., “A 3-D Chimera Grid Embedding Technique” AIAA-1985-1523. AIAA $7^{\text {th }}$ Computational Fluid Dynamics Conference, July, 1985.

${ }^{6}$ Meredith, K.B., Dahlin, J.H., Graham, D.H., Malone, M.B., Haering, E.A. Jr., Page, J.A., and Plotkin, K.J., "Computational Fluid Dynamics Comparison and Flight Test Measurement of F-5E Off-Body Pressures," $43^{\text {rd }}$ AIAA Aerospace Sciences Meeting and Exhibit, AIAA-2005-6, January, 2005, Reno, Nevada.

${ }^{7}$ Spalart, P.R., Allmaras, S.R., “A One-Equation Turbulence Model for Aerodynamic Flows,” AIAA 92-0439.

${ }^{8}$ Toro, E. F., Spruce, M., and Speares, W., "Restoration of the Contact Surface in the HLL Riemann Solver," Shock Waves, Vol. 4, 1994, pp 25-34.

${ }^{9}$ Tramel, R.W., Nichols, R.H., Buning, P.G., “Addition of Improved Shock Capturing Schemes to OVERFLOW 2.1," AIAA-2009-3988. 19 ${ }^{\text {th }}$ AIAA Computational fluid Dynamics, June, 2009.

${ }^{10}$ Chan, W. M., Rogers, S. E., Nash, S. M., Buning, P. G., and Meakin, R. L., "User's Manual for Chimera Grid Tools," Ver. 1.8, NASA Ames Research Center, May 2003

${ }^{11}$ White, F.M., Viscous Fluid Flow, McGraw Hill, Inc., New York, 1974.

${ }^{12}$ Anderson, John D., Modern Compressible Flow With Historical Perspective, $2^{\text {nd }}$ edition McGraw-Hill, Inc., 1992.

${ }^{13}$ Meakin, R.L., "Object X-rays for Cutting Holes in Composite Overset Structured Grids,” AIAA Paper 2001-2537, 2001.

${ }^{14}$ Blake, W.B., "Missile DATCOM User's Manual”, AFRL-VA-WP-TR-1998-3009, Feb. 1998.

${ }^{15}$ Underwood, M.L., et al., "Recent Improvements to Missile DATCOM," $25^{\text {th }}$ AIAA Applied Aerodynamics Conference, AIAA-2007-3936, June, 2007.

${ }^{16}$ Huntun, L.W., Hicks, R.M., Mendoza, J.P., "Some Effects of Wing Planform on Sonic Boom” NASA TN-D-7160, Jan, 1973.

${ }^{17}$ Graham, D.H., Dahlin, J.A., Page, J.A., Plotkin, K.J., Coen, P.G., "Wind Tunnel Validation of Shaped Sonic Boom Demonstrator Aircraft Design," AIAA-2005-7. 43 ${ }^{\text {rd }}$ AIAA Aerospace Sciences Meeting and Exhibit, Jan. 2005.

${ }^{18}$ Casper, J.H., Cliff, S.E., Thomas, S.D., Park M.A., McMullen, M.S., Melton, J.E., and Durston, D.A., "Assessment of Near-Field Sonic Boom Simulation Tools," AIAA-2008-6592, 26 ${ }^{\text {th }}$ AIAA Applied Aerodynamics Conference, Aug. 2008, Honolulu, Hawaii.

${ }^{19}$ Wintzer, M, Nemec, M., Aftosmis, M.J., “Adjoint-Based Adaptive Mesh refinement for Snoic Boom Prediction,” AIAA2008-6593, 26 ${ }^{\text {th }}$ AIAA Applied Aerodynamics Conference, Aug. 2008, Honolulu, Hawaii.

${ }^{20}$ Liou, M.-S., Steffen, C., “A New Flux Splitting Scheme,” J. Comput. Phys., Vol. 107, 23-39, 1993. 1986.

${ }^{21}$ Yee, H.C., "Numerical Experiments with a Symmetric High-Resolution Shock-Capturing System," NASA TM-88325,

${ }^{22}$ Nichols, R.H., Tramel, R.W., Buning, P.G., "Evaluation of Two High Order WENO Schemes," AIAA-2007-3920. 25 AIAA Applied Aerodynamics Conference, June 2007. 


\section{Analysis of the Effects of Streamwise Lift Distribution on Sonic Boom Signature}

Seung Yeun (Paul) Yoo NASA Dryden Flight Research Center 


\section{Outline}

- Introduction

- Method

- Tools \& Validation

- Streamwise Lift Distribution Results

- Conclusion

- Questions 


\section{Introduction}

- Lift and Nozzle Change Effect on Tail Shock

- Engine plume effects (AIAA-2009-1054)

- Streamwise lift distribution effects on shock coalescence

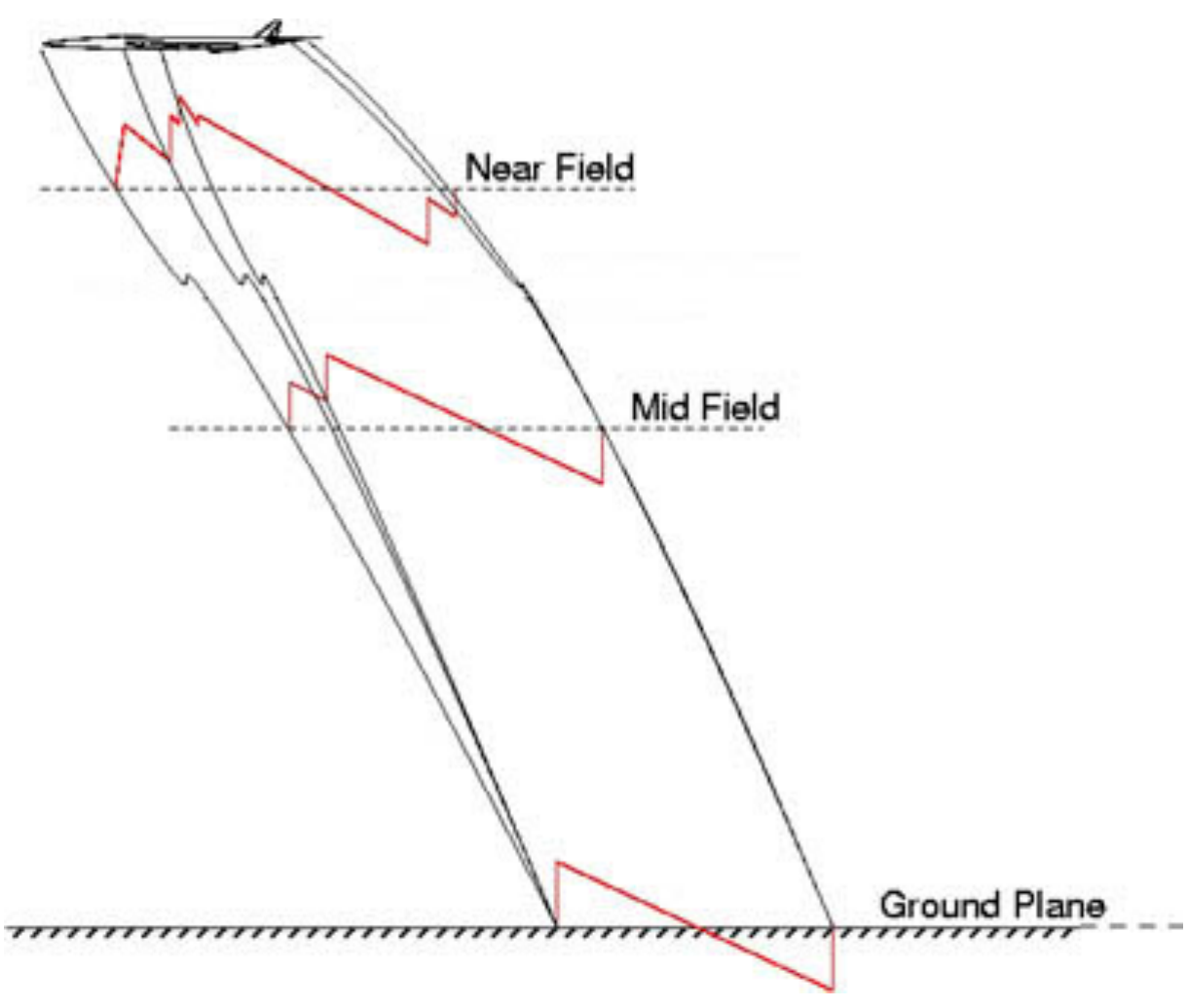




\section{Method: Streamwise Lift Distribution Variation}

- Simple wing-canard-stabilator-body configuration

- Missile DATCOM v.707 for lifting surface deflections

- OVERFLOW-2 for checking and refining

- Inviscid simulation unless viscosity needed

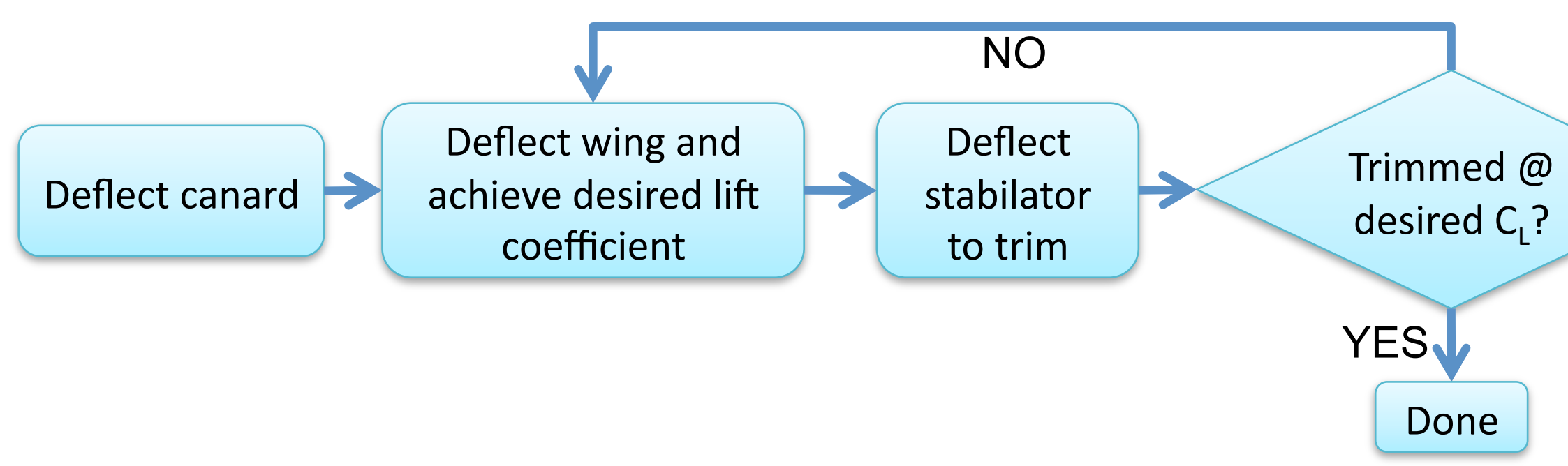




\section{Tools}

\section{OVERFLOW-2 Flow Solver}

- 3-Dimensional, compressible, viscous, Reynolds Averaged Navier-Stokes Solver

- Overset/chimera grid topology

- Multiple turbulence models

- wall-function variation

- DES implementation on some turbulence models

- Steady-State and timeaccurate simulation

- Convergence acceleration schemes

- 6-DOF simulation
Missile DATCOM v.707

- aerodynamic prediction code

- Capable of modeling missile-like geometries with multiple fin stations, protrusions, nozzles, and noses

- Wide range of flight regime

- Validated against wind tunnel as well as CFD 


\section{Validation: Description}

- $69^{\circ}$ delta wing-body

- Symmetrical 5\%c max. thickness at mid. chord diamond airfoil

- wind tunnel data provided in NASA TN D-7160

- $C_{L}=0.00\left(0^{\circ}\right)$ validation

$-C_{L}=0.08\left(2.56^{\circ}\right)$ validation

- Mach 1.68

- Tests:

- Grid Resolution Study

- Numerical Scheme Study

- Missile DATCOM / OVERFLOW-2 comparison
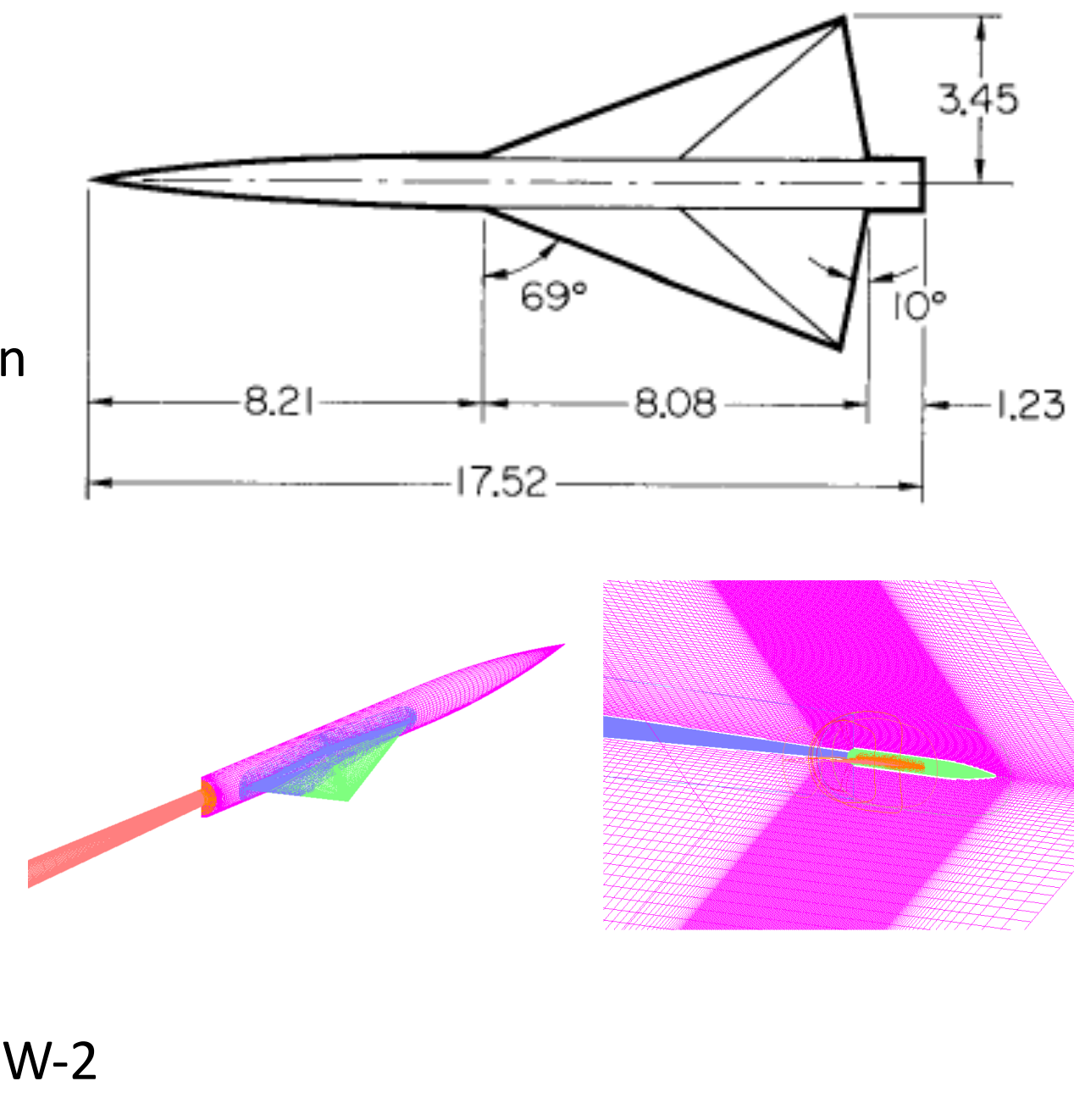


\section{Validation: Grid Resolution Study}

- Zero-lift condition

\begin{tabular}{|c|c|c|c|c|c|}
\hline Grid & $\begin{array}{c}\text { Mach-aligned Far-Field } \\
\text { (JxKxL) }\end{array}$ & $\begin{array}{c}\text { Body } \\
\text { (JxKxL) }\end{array}$ & $\begin{array}{c}\text { Wing } \\
\text { (JxKxL) }\end{array}$ & $\begin{array}{c}\text { Sting } \\
\text { (JxKxL) }\end{array}$ & $\begin{array}{c}\text { Total \# } \\
\text { Grid Point }\end{array}$ \\
\hline $0.5 \mathrm{x}$ & $241 \times 204 \times 89$ & $110 \times 25 \times 25$ & $97 \times 20 \times 25$ & $60 \times 61 \times 25$ & $\sim 4.5 \mathrm{M}$ \\
\hline $1 \times$ & $369 \times 304 \times 89$ & $193 \times 50 \times 50$ & $197 \times 40 \times 50$ & $136 \times 61 \times 50$ & $\sim 11.3 \mathrm{M}$ \\
\hline $2 \times$ & $625 \times 504 \times 145$ & $373 \times 100 \times 100$ & $397 \times 80 \times 100$ & $263 \times 61 \times 100$ & $\sim 54.7 \mathrm{M}$ \\
\hline
\end{tabular}




\section{Validation: Grid Resolution Study Result $\left(C_{\mathrm{L}}=\mathbf{0}\right)$}

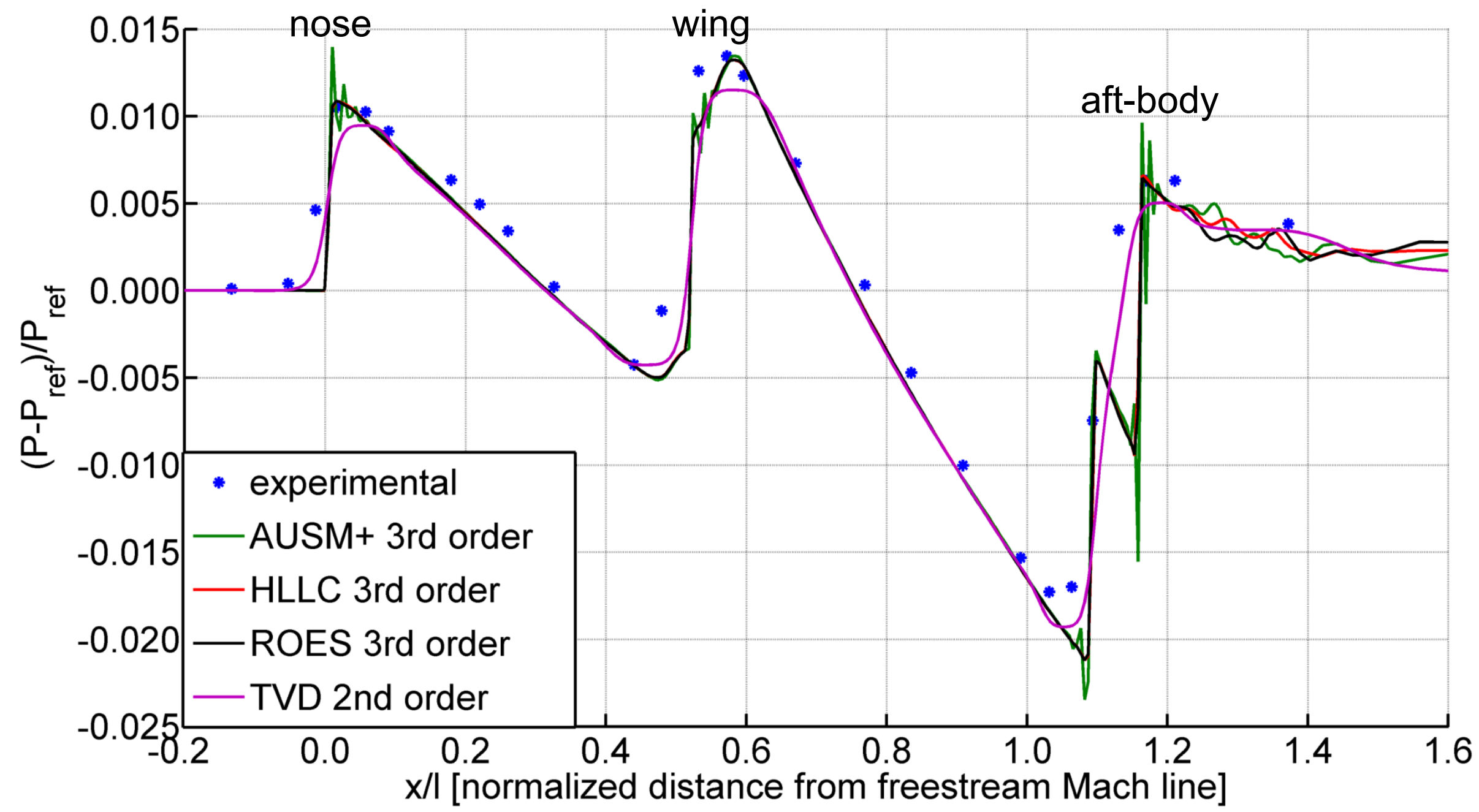




\section{Validation: Numerical Scheme Study}

- Zero-lift condition

- Schemes tested:

- $3^{\text {rd }}$ order Roes Upwind

- $3^{\text {rd }}$ order Advection Upstream Splitting Method (AUSM+)

- $3^{\text {rd }}$ order Harten-Lax-Van Leer with Contact discontinuities (HLLC) Upwind

$-2^{\text {nd }}$ order Total Variation Diminishing (TVD)

$-5^{\text {th }}$ order Weighted Essentially Non-Oscillatory (WENO5)

- $5^{\text {th }}$ order Modified Weighted Essentially Non-Oscillatory (WENO5M) 


\section{Validation: Numerical Scheme Study Result}

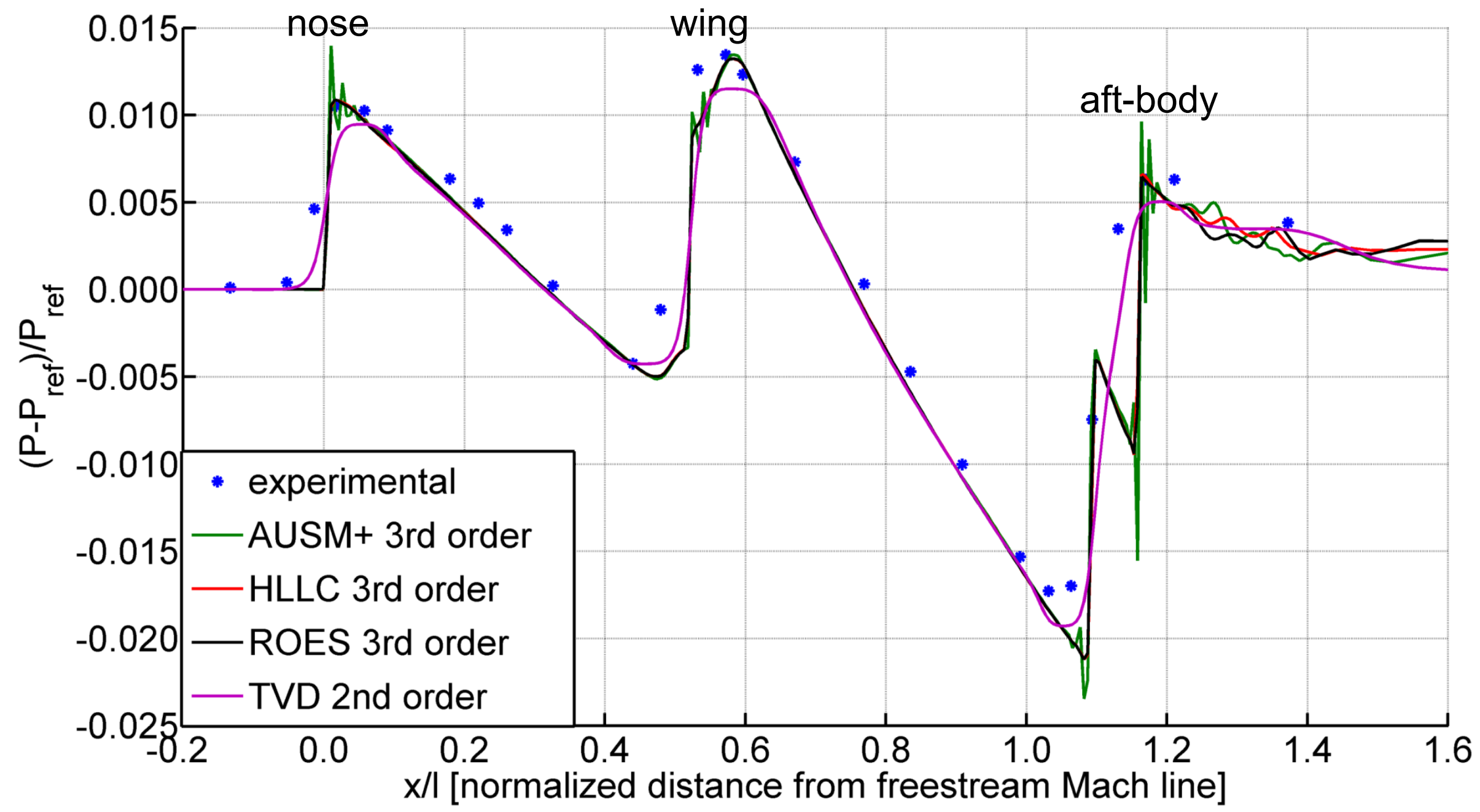




\section{Validation: Numerical Scheme Study Result}

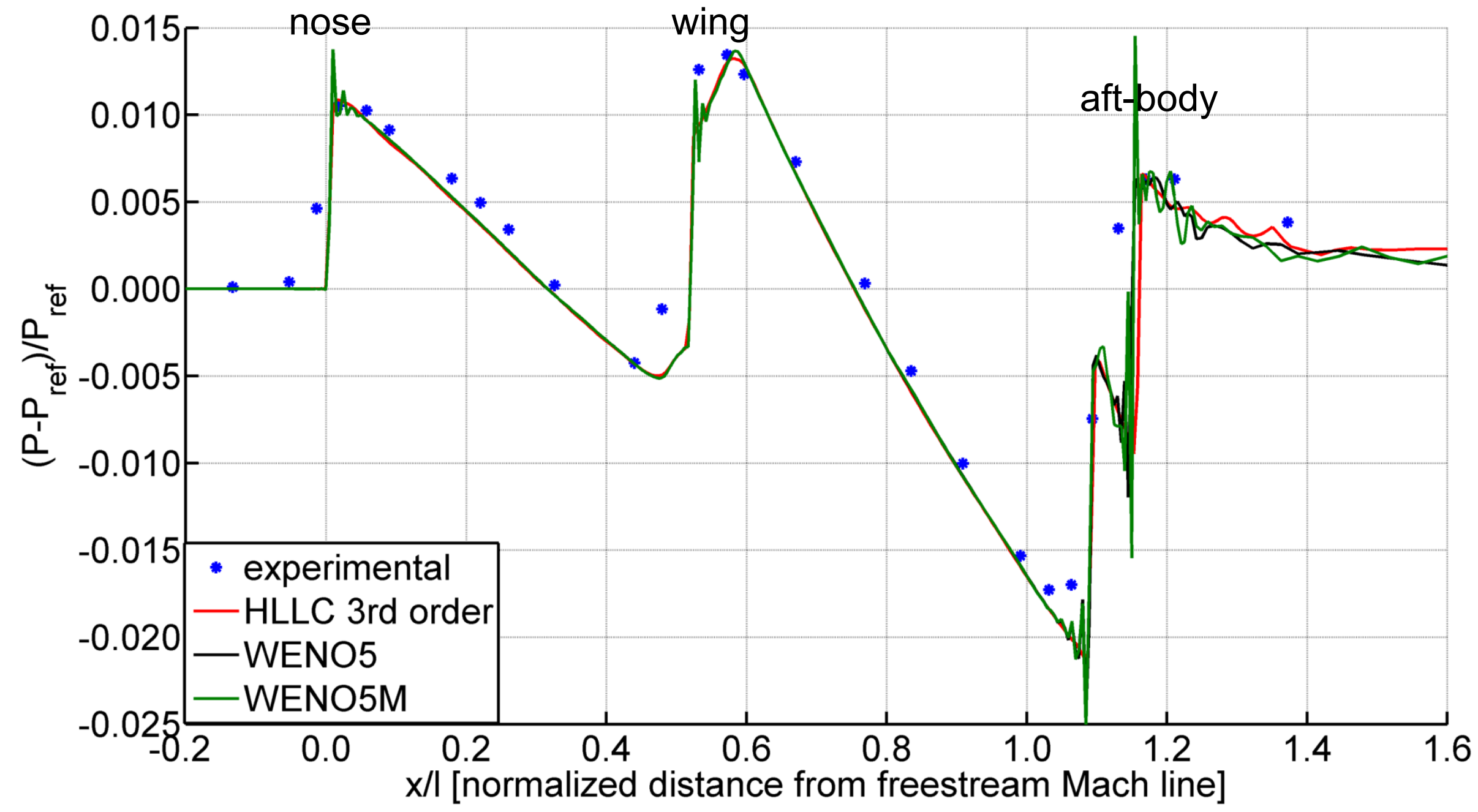




\section{Validation: Lifting Case Result $\left(C_{L}=0.08\right)$}

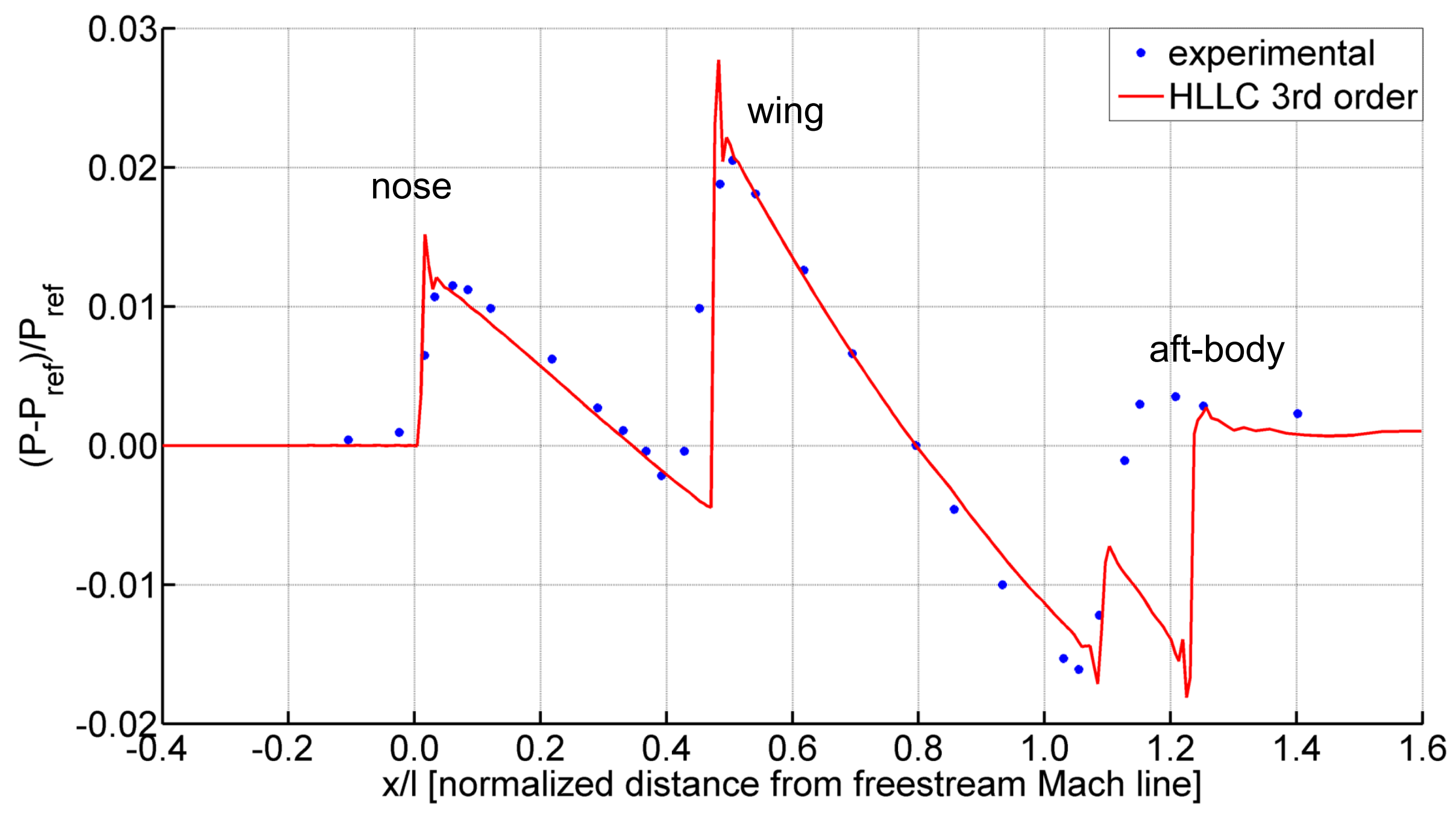




\section{Validation: Missile DATCOM v.707 vs. OVERFLOW- 2}

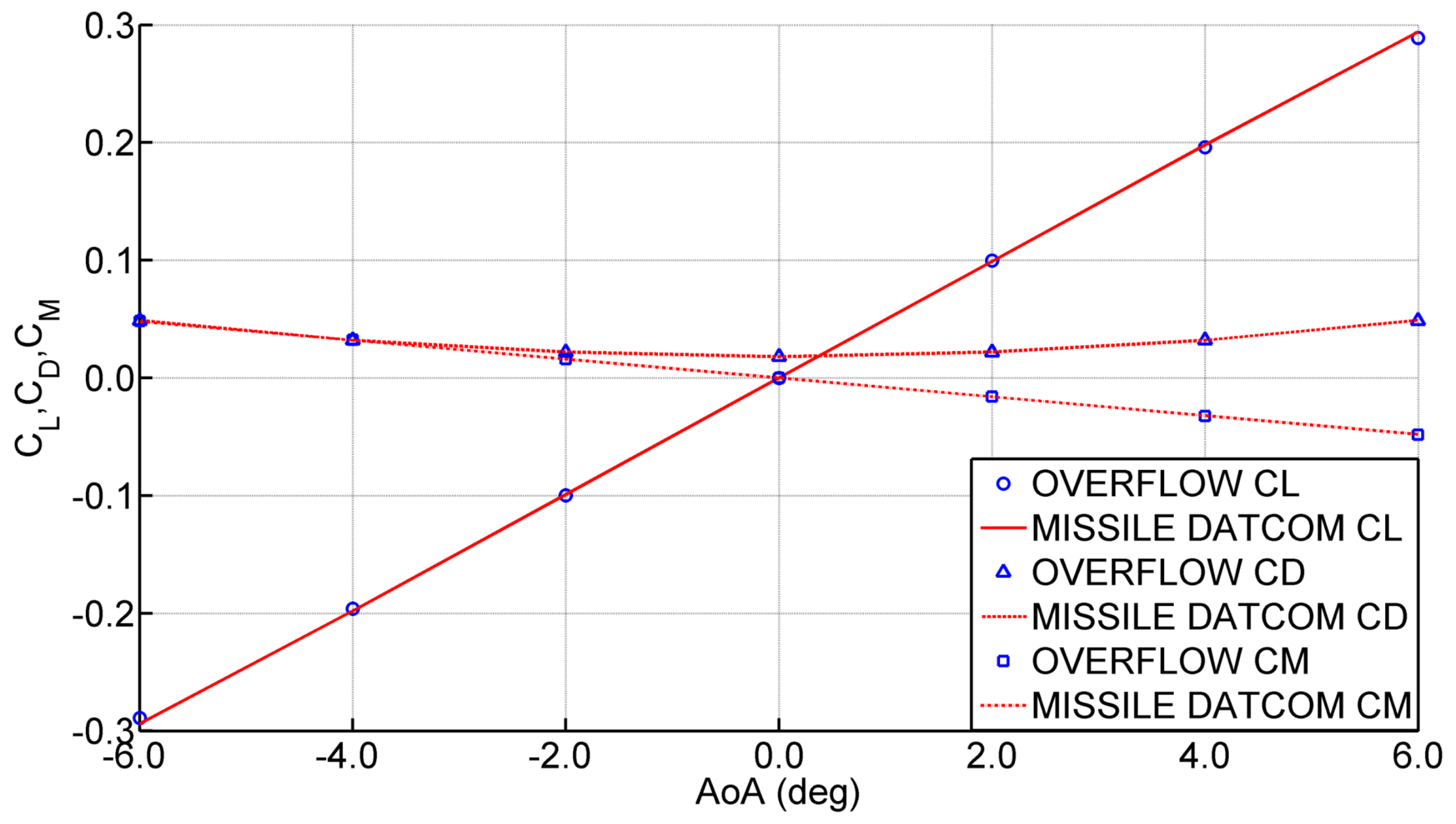




\section{Validation: Result}

- ROES upwind and HLLC upwind schemes produces nearly identical result

- Total Variation Diminishing scheme shows higher dissipation compared to other schemes

- AUSM+, WENO5, WENO5M produces too much unphysical oscillations to be useful for this test

- ROES upwind, HLLC upwind, AUSM+, WENO5, WENO5M agrees well with wind-tunnel measurement

- Missile DATCOM agree well with OVERFLOW-2 for small angle-of-attack

- HLLC chosen for this study

- 1x grid resolution chosen 


\section{Streamwise Lift Distribution: Description}

- Simple wing-canard-stabilator body model

- Propulsion effects (inlets, nozzles) not modeled

- Boat-tail, nose-boom, strake not modeled

- Simplify and accelerate computation and grid generation

— 11 million grid points, 90\% in the Mach-aligned far-field grid

- Some of LaNCETS research A/C features conserved

- Lifting surface span-to-chord ratio

- Lifting surface position relative to nose

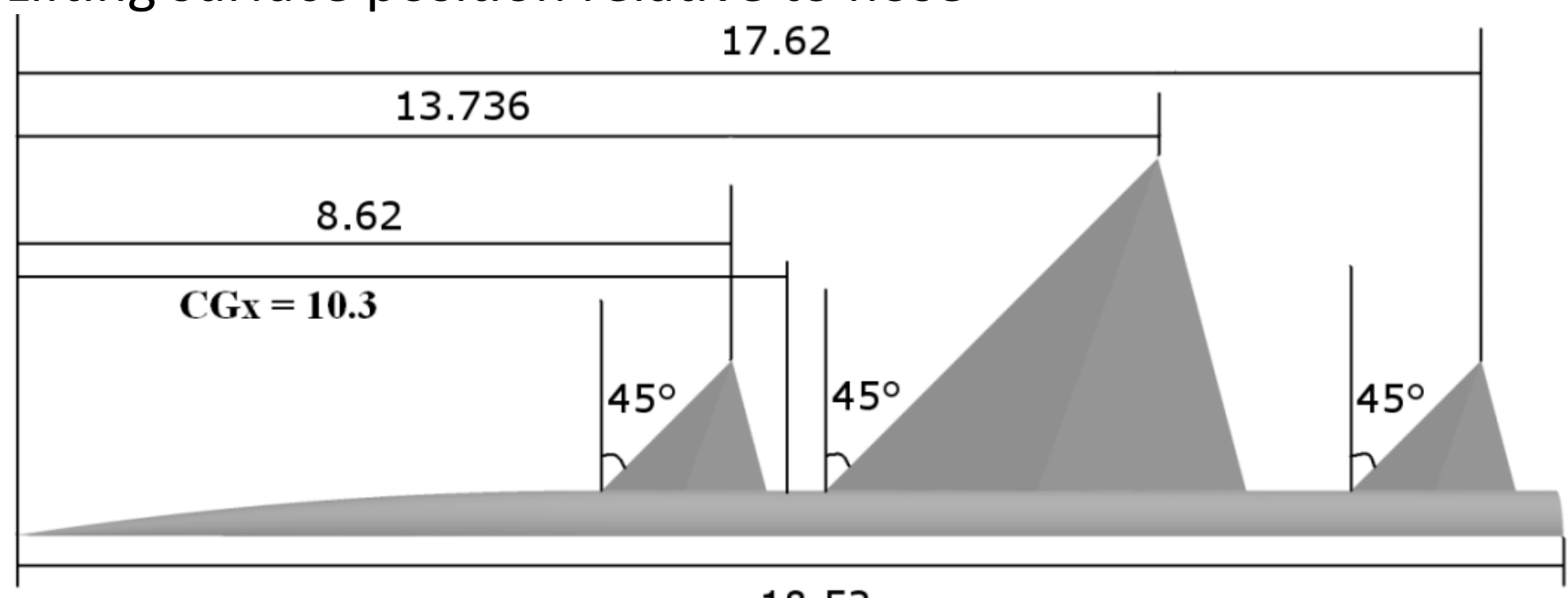




\section{Streamwise Lift Distribution: Test Matrix}

\begin{tabular}{|c|c|c|c|}
\hline Configuration \# & $\begin{array}{c}\text { Canard Deflection } \\
\text { (deg) }\end{array}$ & $\begin{array}{c}\text { Wing Deflection } \\
\text { (deg) }\end{array}$ & $\begin{array}{c}\text { Stabilator Deflection } \\
\text { (deg) }\end{array}$ \\
\hline 1 & -5.5 & 0.3 & -6.0 \\
\hline 2 & 0 & -1.1 & 0.0 \\
\hline 3 & 3.3 & -1.4 & 1.0 \\
\hline 4 & 5.5 & -1.8 & 3.0 \\
\hline
\end{tabular}

*all deflections positive for trailing-edge down

- Configuration 4 simulated with Spalart-Allmaras wall-function turbulence model due to flow separation $\left(\mathrm{y}^{+}=50\right)$

- Mach 1.4

- Constant Angle-of-Attack $=1.5^{\circ}$

- Constant lift coefficient $=0.05$

- Trimmed flight (zero pitching-moment coefficient) 


\section{Streamwise Lift Distribution: Result}

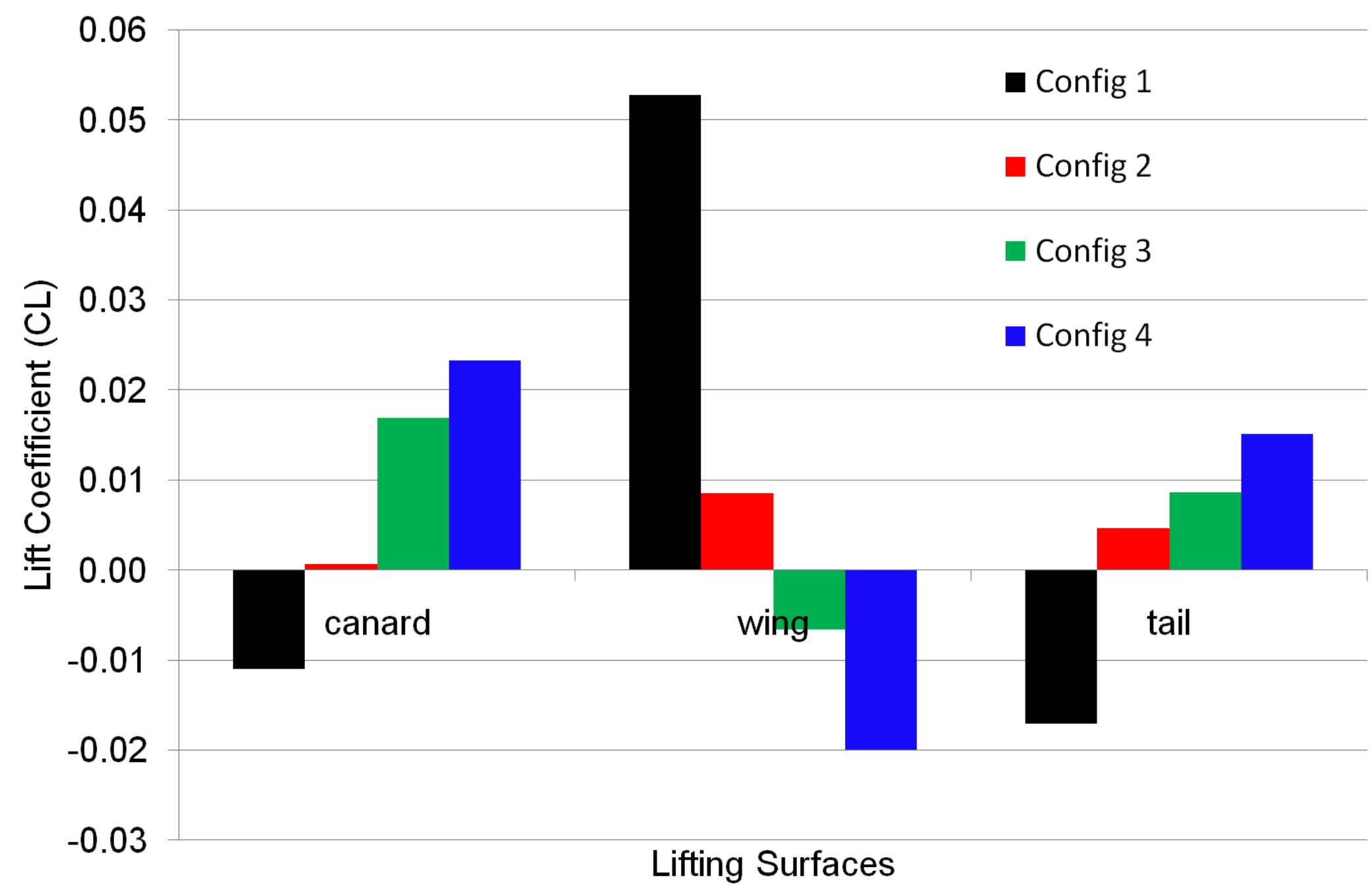




\section{Streamwise Lift Distribution: Result}

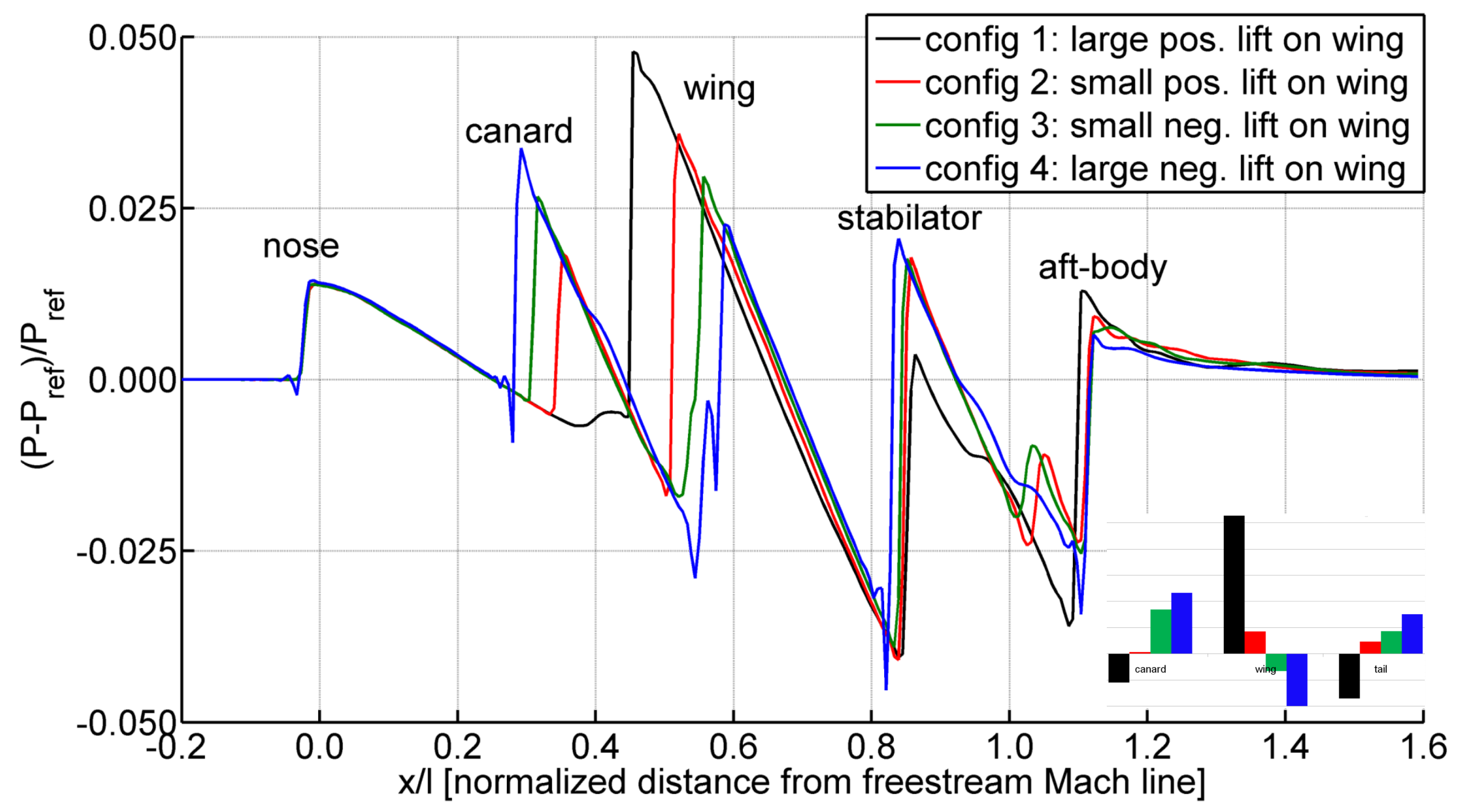




\section{Conclusion}

- Detailed validations of OVERFLOW-2, Missile DATCOM v.707 presented

- The local Mach angle can be varied based on the streamwise lift distribution

- Possible to prevent shock coalescence by distributing lift over the aircraft to create shocks of equal strength 


\section{Questions?}

